\title{
EFECTO DE COMPOST INOCULADO CON BACTERIAS DE LOS GÉNEROS Azotobacter Y Novosphimgobium FIJADORAS DE NITRÓGENO EN EL RENDIMIENTO DEL OLIVO (Olea europaea L.) EN LA YARADA - TACNA, 2011-2012
}

\author{
EFFECT OF COMPOST INOCULATED WITH BACTERIA OF SORTS \\ Azotobacter AND Novosphimgobium NITROGEN-FIXING IN THE PERFORMANCE \\ IN OLIVE (Olea europaea L.) IN THE YARADA - TACNA, 2011-2012
}

${ }^{1}$ Paul Medina Bedoya, ${ }^{2}$ Nivardo Núñez Torreblanca

\begin{abstract}
RESUMEN
El presente trabajo de tesis se realizó en el fundo San Martín de Porras de la empresa BIONDI Y CIA DE TACNA, ubicado en la zona del centro poblado La Yarada en Distrito de Tacna, Región de Tacna, durante la campaña de aceituna 2011 - 2012. El objetivo fue evaluar el efecto del compost mejorado con bacterias fijadoras de nitrógeno de los géneros Azotobacter y Novosphimgobium en el rendimiento del olivo. El material experimental utilizado fue un compost de hoja de olivo con las bacterias fijadoras de nitrógeno, en un diseño experimental aleatorio, con 5 tratamientos, el primero como testigo sin ninguna aplicación de fertilización nitrogenada, seguido del tratamiento con $16 \mathrm{~kg}$ de compost por planta, el tercero con $32 \mathrm{~kg}$ de compost por planta, el cuarto con $48 \mathrm{~kg}$ de compost por planta y el ultimo con fertilización nitrogenada química; a su vez se realizaron 8 repeticiones, totalizando 40 plantas en experimentación. El campo experimental consta de 0,45 has con una densidad de siembra de 100 plantas por hectárea. Los resultados demostraron que se encontró diferencia entre los rendimientos siendo el mejor la fertilización química, igualmente se encontró que los mejores niveles de nitrógeno en suelo y mejores calibres fueron del tratamiento con aplicación de $48 \mathrm{~kg}$ de compost mejorado por olivo con 0,45\% de $\mathrm{N}$ en suelo y calibres promedio de 294 frutos por kilogramo para aceituna verde y 179 frutos por kilogramo para aceituna negra.
\end{abstract}

Palabras clave: Olivo, materia orgánica, microorganismos.

\section{ABSTRACT}

This thesis work was performed at the San Martin de Porras farm company BIONDI Y CIA TACNA, located in the village center in the District Yarada Tacna, Tacna Region, during the olive season 2011-2012. The aim was to evaluate the effect of improved nitrogen-fixing bacteria of the genera Azotobacter and performance Novosphimgobium olive compost. The experimental material used was an olive leaf compost with nitrogen fixing bacteria, in a randomized experimental design with 5 treatments, the first witness without any application of nitrogen fertilization, followed by treatment with $16 \mathrm{~kg}$ of compost per plant, third with $32 \mathrm{~kg}$ of compost per plant, the fourth with $48 \mathrm{~kg}$ of compost per plant and the last with chemical nitrogen fertilizer, in turn 8 repetitions were performed, totaling 40 plants in experimentation. The experimental field consists of 0,45 hectares with a seeding density of 100 plants per hectare. The results showed that differences were found between the yields the being the best chemical fertilization, also is found that the highest levels of nitrogen in soil and calibres were best the treatment application $48 \mathrm{~kg}$ per tree compost enhanced with $0,45 \% \mathrm{~N}$ in soil and the average sizes of 294 fruits per kilogram and 179 olive fruits per kilogram for black olive.

Keyword: Olive, organic matter, microorganisms.

\section{INTRODUCCIÓN}

El cultivo del olivo en el Perú ha crecido en los últimos años debido a que es un cultivo muy rentable en las costas del sur del país llegando a exportar a Brasil, Chile,
EEUU, Japón, Argentina, lo que manifiesta el crecimiento de la demanda de la aceituna peruana, es así que en Tacna se ha incrementado hasta 15 mil hectáreas de olivo (Dirección Regional de Agricultura Tacna 2012); siendo unos de los principales inconvenientes para poder realizar un cultivo

\footnotetext{
Ingeniero Agrónomo, Especialista en Olivicultura y Elaiotecnia. Empresa Biondiy Cia. de Tacna. Tacna-Perú.

Ingeniero Agrónomo, Msc. en Agricuitura Andina. Docente de la Facultad de Ciencias Agropecuarias de la Universidad Nacional Jorge Basadre Grohmann. Tacna- Perú
} 
Medina, P. \& Nuñez, N. Efecto del compost inoculado con bacterias de los géneros Azabactery Novosphimgobium fijadoras de nitrógeno en el rendimiento del olivo

ecológico la fertilización y dentro de esta la fertilización nitrogenada, por lo cual con este estudio procuramos brindar una alternativa de solución para poder incorporar dicho elemento, a través de la hipótesis de que un abono mejorado con bacterias nitrificantes logran sintetizar dicho elemento en el suelo y hacerlo disponible para que las raíces del olivo puedan absorberlo, incrementando el rendimiento.

Las bacterias nitrificantes de los géneros Azotobacter y Novosphimgobium son bacterias que fijan nitrógeno de manera asociativa con las plantas, bajo condiciones de humedad y materia orgánica, con $\mathrm{pH}$ ligeramente alcalino.

Con dichas bacterias se pueden preparar inoculantes los cuales después de ser aplicados sobre un compost, preparado a base de hojas de olivo, permiten disminuir el empleo de fertilizantes nitrogenados, tal como muestran pruebas en otros países con dichas bacterias donde mejora la cantidad de nitrógeno y rendimiento de los cultivos Martínez et al. (1999).

El presente trabajo se realizó en condiciones de campo con olivos en producción con la finalidad de probar las bacterias con respecto a los rendimientos del cultivo del olivo, las cantidades de nitrógeno que logra acumular la planta en hoja y cantidades de nitrógeno en suelo.

\section{MATERIALES Y MÉTODOS}

El presente trabajo experimental se realizó en el Fundo San Martín de Porras propiedad de la empresa Biondi y Cía de Tacna, ubicado en la zona de "La Esperanza" Yarada - Baja. Dicho fundo se encuentra a $34 \mathrm{~km}$ de la ciudad de Tacna.

Se consideraron 5 tratamientos con 8 repeticiones cada uno totalizando 40 olivos en experimentación. Las cantidades de kilogramos en la tabla 1 se refieren a kilogramos de compost ya inoculado con las bacterias.

Tabla 1. Tratamientos.

\begin{tabular}{ccc}
\hline Tratamientos & Kilogramo por & Kilogramo por hectárea de \\
\hline T1(testigo absoluto) & 0 & 0 \\
T2 & 16 & 1600 \\
T3 & 32 & 3200 \\
T4 & 48 & 4800 \\
T5 (testigo) & Fertilización química & 80 unidades de N
\end{tabular}

Se preparó el material experimental a base de compost de hoja de olivo en una relación de 1 cantidad de hoja de olivo y 1 cantidad de estiércol de vacuno, luego del proceso de compostaje se realizó la inoculación con las bacterias preparadas en laboratorio, la cantidad utilizada de estas bacterias fue de unos 3 litros de Azotobacter $\left(1 \times 10^{9}\right.$ $\mathrm{UFC} / \mathrm{ml}$ ) y 6 litros de Novosphimgobium $\left(4 \times 10^{8} \mathrm{UFC} / \mathrm{ml}\right)$, todo en un aproximado de $750 \mathrm{~kg}$ de compost. Posteriormente se realizó el proceso de incorporación del compost en el campo de acuerdo a cada tratamiento, el momento de incorporación fue al inicio de campaña del olivo, alrededor de las plantas de olivo según el riego por goteo.

El manejo del campo de olivo, no presentó ninguna alteración a manera de poder obtener los datos en condiciones normales de producción, por lo que el resto de fertilización se incorporó vía sistema de riego, en el caso del trata- miento T5 se tuvo una fertilización normal con 80 unidades de nitrógeno, con un manejo integrado de plagas y enfermedades, las podas y la cosecha se realizó manualmente tal como se realiza en el resto del fundo.

\section{RESULTADOSY DISCUSIÓN}

\section{Rendimientos}

Según la tabla 2, para la variable rendimiento el mejor resultado lo obtuvo el tratamiento T5 con fertilización química con un promedio de 18 toneladas de aceituna por $\mathrm{Ha}$, lo que indica que la fertilización química es mejor para la variable rendimiento con respecto a la fertilización con las bacterias nitrificantes, esto debido a que la fertilización química tiende a tener mayor efecto a corto plazo.

Tabla 2. Rendimientos expresados en $\mathrm{Kg} /$ ha según tratamientos.

\begin{tabular}{ccccc}
\hline T1 & T2 & T3 & T4 & T5 \\
\hline 12413 & 13947 & 14525 & 15142 & 18478 \\
\hline
\end{tabular}

El tratamiento T4 quedo en segundo lugar con un $18 \%$ menos en rendimiento comprado al tratamiento $\mathrm{T} 5$, lo que demuestra la importancia de la inoculación con dichas bacterias, que según algunos autores debe ir incrementando en el tiempo la cantidad de nitrógeno hasta llegar a estabilizar y producir tan igual como una fertilización química.

\section{Calibre aceituna negra}

Se realizó un ANVA con los números de frutos por kilogramo en promedio por tratamiento, el cual indico que no existe diferencias significativas, pero por un margen muy pequeño, por lo que se realizó una prueba de significación de DUNCAN para obtener el mejor calibre, siendo este el mejor el tratamiento T4 con 179 frutos, seguido del T5 con 184, el T2 con 207, y T1 y T3 con 216 y 217 siendo las de menor calibre, según la tabla 3.

Tabla 3. Prueba de significación de calibre de aceituna negra

\begin{tabular}{|c|c|c|c|}
\hline Tratamientos & $\begin{array}{l}\text { Numero de } \\
\text { frutos/kg. }\end{array}$ & & Significación \\
\hline $\mathrm{T} 4$ & 179,3 & a & \\
\hline T5 & 184,3 & $a b$ & \\
\hline $\mathrm{T} 2$ & 207,9 & & $a b c$ \\
\hline T1 & 216,8 & & \\
\hline T3 & 217,5 & & \\
\hline
\end{tabular}

Según los calibres se encontró que los más predominantes fueron los rangos de 150-180 y 180-210, obteniendo el promedio del tratamiento $\mathrm{T} 4$ dentro de este rango.

\section{Calibre de aceituna verde}

Se realizó una ANVA con los números de frutos por kilogramo de peso por tratamiento, obteniendo un resultado no significativo por mucha diferencia, con un CV de 14, debido a que existe mucha diferencia en la significación no se realizó Duncan, por lo que para los calibres de aceituna verde no existe ninguna influencia estadísticamente de parte de los tratamientos con compost mejorado; sin embargo al 
Medina, P. \& Nuñez, N. Efecto del compost inoculado con bacterias, de los géneros Azobactery Notosphimgobium fijadoras de nitrógeno en el rendimiento del olivo

realizar una evaluación por calibres logramos encontrar que el mejor promedio lo obtuvieron el tratamiento T3 y T4 con 291 y 294 frutos por kilogramo promedio, y en rango de calibres que mejor fue de 320 a 400 . Se notó que el tratamiento T2 obtuvo el menor calibre con 334 frutos por kilogramo.

Se logra observar que el tratamiento T5 tiene mayor cantidad de frutos por lo que mejora sus rendimientos pero disminuye sus calibres aunque para la variable calibre son estadísticamente iguales.

\section{Cantidad de nitrógeno en hoja}

Para realizar el nitrógeno en hoja se tomó muestras durante todo el periodo de producción del olivo iniciando en el mes de julio hasta el mes de agosto del siguiente año. Se logra observar que en los meses de invierno se obtiene niveles de nitrógeno en hoja de 1,5 a más, solo para los tratamientos T4 y T5, más para los otros tratamientos no fue favorable, esto es corroborado por los autores Champan (1966), Childers (1966), y Beutel et al. (1983), el tratamiento T1 como era de esperarse obtuvo el menor valor con 1.18 un nivel considerado deficiente. Los tratamientos T3 y T2 con niveles de 1,23 y 1,21 respectivamente.

La curva que realiza el nivel de nitrógeno en hoja en los tratamientos según Barranco et al. (1999) tienden a disminuir en los meses de reposo invernal, siendo esto corroborado con los resultados obtenidos (figura 1) ya que los niveles de nitrógeno disminuyeron en dicho meses e incrementan posteriormente a los meses de verano. Esto también es referido por datos en los trabajos de tesis Bueno (2010), que pone de manifiesto que en un periodo de 4 años obtuvo promedios de niveles de nitrógeno los cuales disminuyen en reposo invernal, incrementando con la llegada de la primavera y el desarrollo de los frutos llegando a un pico alto en la maduración del fruto, siendo esto los meses de verano, para luego volver a decaer con la llegada del otoño e invierno.

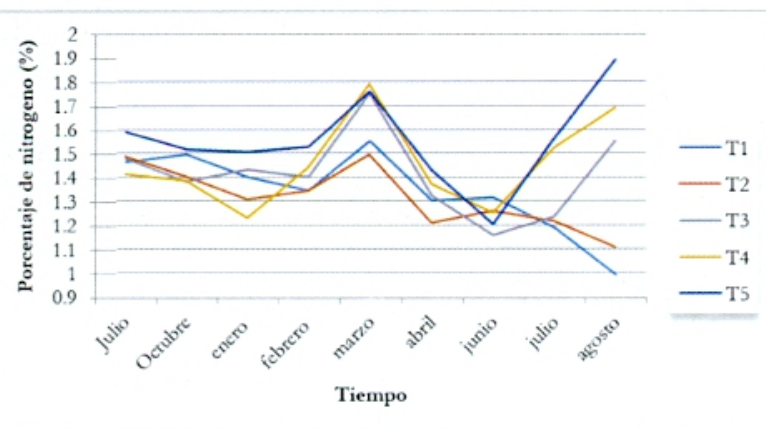

Figura 1. Niveles de nitrógeno en hoja según tratamiento.

\section{Cantidad de nitrógeno en suelo}

Se tomó tres muestras al inicio en marzo y al finalizar la campaña con lo que se logró una curva en lo cual desciende en los meses de verano y asciende en los meses de invierno. Según la tabla 4 los mejores niveles de nitrógeno en suelo al finalizar la campaña fueron de los tratamiento T4 y T3 con 0,44 y 0,43 , lo cual nos indica que la aplicación del compost mejorado con las bacterias nitrificantes influyo en la fijación del nitrógeno al suelo incluso en mayor cantidad que la de fertilización química esto debido a que las bacterias son las
Tabla 4. Cantidad de nitrógeno (\%) en suelo según tratamientos

\begin{tabular}{cccccc}
\hline & T1 & T2 & T3 & T4 & T5 \\
\hline Julio & 0,198 & 0,208 & 0,225 & 0,268 & 0,205 \\
Marzo & 0,126 & 0,184 & 0,209 & 0,139 & 0,183 \\
Agosto & 0,121 & 0,329 & 0,432 & 0,449 & 0,305 \\
\hline
\end{tabular}

que logran obtener el nitrógeno de la atmósfera fijándolo por medio de la fijación asociativa gracias al intercambio de sustancias entre dichas bacterias y a zona de la rizósfera, estos datos reflejan lo dicho por Hernández et al. (1994).

\section{CONCLUSIONES}

El efecto de compost inoculado con las bacterias fijadoras de nitrógeno en el rendimiento del olivo mostró que el tratamiento con fertilización química (80 unidades de nitrógeno) obtuvo un rendimiento de $18478 \mathrm{~kg} / \mathrm{Ha}$, siendo este el mejor de la prueba; sin embargo, el tratamiento T4 (48 $\mathrm{kg}$ de compost mejorado/planta) muestra un rendimiento de $15141 \mathrm{~kg} /$ Ha siendo el segundo mejor.

Los calibres tanto de aceituna verde como de negra no muestran diferencias entre sí, por lo que los tratamientos aplicados influyen de manera similar en dicha variable, cabe destacar que el tratamiento T4 (48 kg/planta de compost mejorado) mostró mejores calibres para la comercialización.

Los niveles de nitrógeno en hoja de olivo para los tratamiento T5 (fertilización química) y T4 (4800 kg/ha de compost mejorado) mostraron resultados dentro de los parámetros recomendados 1,56 y 1,52 respectivamente, lo cual indicó que la aplicación del compost mejorado a una cantidad de $48 \mathrm{~kg} /$ planta logra cubrir la necesidad de nitrógeno en hoja al igual que la fertilización química.

Para el contenido de nitrógeno en suelo las aplicaciones de compost mejorado influenciaron en mejor cuantía que la fertilización química, siendo el tratamiento T4 el de mayor resultado con un nivel de nitrógeno en suelo al final de la campaña que fue de $0,45 \%$.

\section{REFERENCIAS BIBLIOGRÁFICAS}

Barranco, D., Escobar, F. y Rallo, L. (1999). El cultivo del olivo. 3ra Edición. Barcelona, España: Editorial Mundi, 651 pp.

Bueno Grimalt L. A. (2010). Análisis de los cambios estacionales y efecto de las diferentes zonas sobre la concentración de nutrientes en hojas de olivo (Olea europaea L.) en San Juan. - Instituto Nacional de Tecnología Agropecuaria, Estación Experimental Agropecuaria San Juan, 72 pp.

Consejo Oleícola Internacional. (19969. Enciclopedia mundial delOlivo-1 ra. Edición. España, 479pp.

Fernández Escobar (2001). Boletín informativo el abono nitrogenado en la producción del aceite. Córdoba España, 22 pp.

Fuentes, J. L. (1980). Elsuelo y los fertilizantes. Madrid España: Ediciones Mundi Prensa, $257 \mathrm{pp}$.

Hamdi, Y. A. (1985). La fijación del nitrógeno en la explotación de los suelos. Boletín de Suelos. FAO. Roma, 


\section{Ciencia \& Desarrollo}

Medina, P. \& Nuñez, N. Efecto del compost inoculado con bacterias de los géneros Azobactery Nonosphimgobium fijadoras de nitrógeno en el rendimiento del olivo

$188 \mathrm{pp}$.

Hernández, M., Pereira M. y Tang. M. (1994). Utilización de microorganismos Biofertilizantes en los cultivos tropicales. Pastos y Forrajes, pág. 183-192.

Martin Alexander. (1980). Microbiología del suelo. 2da Edición. Libros y Editoriales S. A., 483 pp.

Martínez, R., Toledo, L., García, R. y Arguelles, C. (1999). Introducción al conocimiento sobre los biofertili- zantes. Documento en imprenta Universidad Tecnológica de la hausteca hidalguense Instituto de Investigaciones Fundamentales en Agricultura Tropical (INIFAT) Cuba.

Mishustin, E. N. and Silnikova, E. K. (1971). Fijación biológica del nitrógeno atmosférico MC. Millan, Italia: Ed. Londres, 675 pp.

\section{Correspondencia:}

Nivardo Nuñez Torreblanca: ntor_01@hotmail.com
Fecha de Recepción: 06/05/2015

Fecha de Aceptación: 02/12/2015 